\title{
EFFECT OF POSTURE ON VENOUS VELOCITY, MEASURED WITH ${ }^{24} \mathrm{NaCl}$
}

\author{
BY \\ H. PAYLING WRIGHT AND S. B. OSBORN \\ From University College Hospital and Medical School \\ Received October 28, 1951
}

The importance of posture in the venous return to the heart from the lower limbs in normal and pathological conditions has been recognized for over a century. As early as 1826 , Piorry noted that the effect of gravity could produce syncope in subjects kept in the upright posture and that the attack was relieved when the patient lay down. Marshall Hall (1832) carried out animal experiments which showed that the venous return was, to a great extent, dependent upon posture and that the blood in the limbs was directly controlled by gravity. In man, a clue to the mechanism whereby blood is propelled from the lower limbs against the force of gravity is given by the presence of valves in the veins, an adaptation unnecessary in animals that have not assumed the upright gait.

At the same time that these concepts of circulatory control were being investigated, the importance of venous stasis as a factor in the onset of thrombosis was being emphasized. For many years experimental observations on blood flow in the lower limbs have been made both to investigate what conditions may modify venous velocity and also what are the best modes of preventing the occurrence of venous thrombosis.

The methods for measuring such flow-rates have been many and varied, but it was not until the introduction of radioactive substances that a direct and simple technique could be devised. The following observations not only support and amplify the results obtained with earlier and less direct methods, but also give mean flow-rate values under various postural conditions compared with a standard, the repeatability of which is discussed.

Methods. The technique of measuring venous flow-rates in the legs was identical with that previously described (Wright et al., 1948; Osborn and Wright, 1949). Briefly, a small volume (0.2$1.0 \mathrm{ml}$.) of physiological saline containing $2-5 \mu \mathrm{c}$. of ${ }^{24} \mathrm{Na}$ is injected intravenously in the foot under standard conditions of temperature, rest, and posture. Through the use of a screened GeigerMüller counter placed over the femoral triangle, the injected material is detected in the venous stream when it arrives at the groin. By means of a suitable circuit, impulses from the counter are recorded on a kymograph drum, the tracing from which shows the moment of injection, the instant when the radioactive substance passes under the counter, and a suitable time marker. From these data, the distance between the point of injection and the femoral triangle having been measured, the mean rate of venous flow can be deduced.

For each of the following groups of cases, the standard flow-rate was recorded for each subject under controlled conditions (Wright et al., 1948). To insure comparable results, the subject rests for 20 minutes with the legs immersed to the knees in a water bath at $40^{\circ} \mathrm{C} .:$ at this temperature, vasodilation is complete. The subject lies flat in the supine position with the heel at the same level as the heart while the injection is made and the tracing obtained. For comparison with the observation made under these standard conditions, the test measurement was made immediately afterwards 
through the same needle which was left in situ in all cases except those of Groups 1 and 2. Normal subjects, men and women, were used for each group of observations; their ages ranged from 16-57 years. No subject suffering from varicose veins was included.

The conditions under which venous flow-rates in the legs were investigated were as follows.

1. Repeated observations in the same leg at weekly intervals, under standard conditions.

2. Comparison of flow-rates of right and left legs on a single occasion, under standard conditions.

3. Comparison of flow-rates in standard (lying) and standing positions.

4. Comparison of flow-rates in standard and sitting (legs down) positions.

5. Comparison of flow-rates in standard and crossed-knee sitting positions.

6. Comparison of flow-rates in standard and head down lying positions, the body inclined at 10 degrees to the horizontal.

7. Comparison of flow-rates under standard conditions before and after vigorous dorsi- and plantar- flexion of the foot for 2 minutes.

\section{RESULTS}

The findings for the first two groups of observations, with their standard errors and co-efficients of variation are set out in Table $I$. These are based upon 48 individual measurements made on 4 normal volunteers, whose venous flow-rates in both right and left legs were measured on each of six occasions under standard conditions.

TABLE I

Flow-RATE IN 4 Normal Subjects

\begin{tabular}{|c|c|c|c|c|}
\hline \multirow[b]{2}{*}{ Subject } & \multicolumn{2}{|c|}{ Right leg } & \multicolumn{2}{|c|}{ Left leg } \\
\hline & $\begin{array}{c}\text { Flow rate, } \\
\mathrm{cm} . / \mathrm{sec} .\end{array}$ & $\begin{array}{c}\text { Co-efficient } \\
\text { of variation } \\
(\%)\end{array}$ & $\begin{array}{c}\text { Flow rate, } \\
\mathrm{cm} . / \mathrm{sec} .\end{array}$ & $\begin{array}{c}\text { Co-efficient } \\
\text { of variation } \\
(\%)\end{array}$ \\
\hline $\begin{array}{l}1 \\
2 \\
3 \\
4\end{array}$ & $\begin{array}{l}5 \cdot 1 \pm 0 \cdot 45 \\
2 \cdot 5 \pm 0 \cdot 11 \\
3 \cdot 9 \pm 0 \cdot 24 \\
5 \cdot 3 \pm 0 \cdot 25\end{array}$ & $\begin{array}{l}20 \\
10 \\
14 \\
11\end{array}$ & $\begin{array}{l}4 \cdot 6 \pm 0 \cdot 30 \\
2 \cdot 6 \pm 0 \cdot 24 \\
3 \cdot 8 \pm 0 \cdot 40 \\
5 \cdot 6 \pm 0 \cdot 38\end{array}$ & $\begin{array}{l}15 \\
21 \\
24 \\
15\end{array}$ \\
\hline Average & $4 \cdot 20$ & & $4 \cdot 15$ & \\
\hline
\end{tabular}

It can be seen that, while the observations made on the two legs are in every instance closely similar, the flow-rates vary very considerably from one subject to another. The coefficient of variation gives a measure of repeatability on different occasions and this is of such an order that these observations may be said to fall within the same statistical group. When larger groups of measurements are analysed, the average flow-rates are found to agree remarkably closely under standard conditions as shown by the average results of $4.2 \mathrm{~cm}$. sec. in Table I and by the findings for the various groups in Table II.

The extent to which changes in posture (Groups 3-7) alter the flow-rate from that in the standard recumbent position is shown in Table II. Fifteen sets of paired observations were made for each group, from which data the averages and standard errors were derived. The probability $(p)$ that the paired values were significantly different was calculated by Fisher's method.

The paired material shows highly significant differences in every group except the crossed-knee sitting position (Group 5). It is noteworthy that the venous velocity was diminished in both the standing and the sitting (legs down) positions while the reverse, an increased velocity, occurred in the head-down position and after foot exercises. 
TABLE II

FLOW-RATE IN VARIOUS Positions

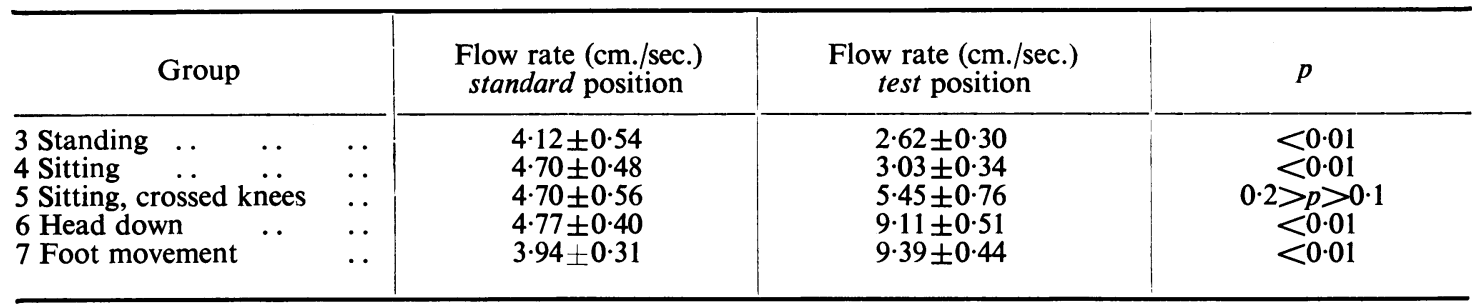

\section{DisCUSSION}

From time to time it has been suggested that variations in the venous flow-rate in the lower limbs are responsible for local stagnation and hence the far greater incidence of thrombosis in these blood vessels than in those of the arm. Clinically it has been stated that such thrombotic complications occur more commonly in the left than in the right leg. The following short table (Table III) sets out a few of the available series analysed from this view point. It must be stressed that these figures are based on clinical observations and not on autopsy findings.

TABLE III

Site of Venous Thrombosis in Cases of Pulmonary Embolism

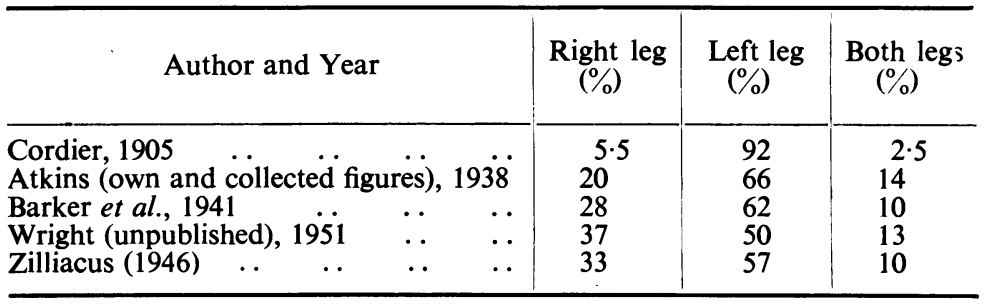

The explanation put forward for this difference between the two sides is based on anatomical considerations. The sigmoid colon and the common iliac artery are stated to press upon the left common iliac vein, thus causing venous occlusion of varying degrees. The consequent retardation of venous velocity on that side might, therefore, be favourable to thrombus formation. Careful autopsy examinations, however, have not revealed that the incidence of thrombi is, in fact, more common on the left than on the right; indeed, Hunter et al. (1941) in his large series found a slight preponderance on the right (206:191), while Ingram (1942), though without giving figures, states that in his series of autopsies, thrombi were discovered as frequently on the right as on the left. We have obtained from the post-mortem reports of cases dying of pulmonary embolism during the past five years (1947-51) in two of the large London Teaching Hospitals (Guy's and U.C.H.) the number of emboli ascertained to have arisen from the two sides of the body. Of 106 deaths recorded, the embolus originated in the right leg in 60 instances while only 46 had come from the left. Such figures do not, of course, constitute any proof that thromboses are more common in the right leg than in the left, but they do suggest that the clinical and autopsy figures may be different. It may be that the typical signs of thrombosis are for some reason more easily recognized during life when they occur on the left side.

Measurement of flow-rates in the two lower limbs has not disclosed any abnormal slowing of the blood stream on the left. Kvale and Allen (1939), using the magnesium sulphate method, found a mean leg-tongue time of $34.28 \pm 0.85 \mathrm{sec}$. on the right, and of $34.0 \pm 0.85 \mathrm{sec}$. on the left. Our more direct method of measuring venous flow-rates has failed to show any significant difference between 
the two sides (see Table I), the right giving an average of $4 \cdot 20 \pm 1 \cdot 3 \mathrm{~cm}$. sec. and the left, $4 \cdot 15 \pm 1 \cdot 8$ $\mathrm{cm}$. sec. It seems unlikely, therefore, that any observed preponderance of clinically diagnosed thrombi in the left leg can be directly referable to any inherent difference in venous velocity on the two sides.

In experimental work, repeated observations on the same subject on different occasions are frequently made. It was necessary, therefore, to determine the variability of our method and to have some measure of the day to day fluctuations that might be expected. For this purpose four volunteers were examined at weekly intervals for six weeks, the observations being made under standard conditions on each occasion. Fishberg et al. (1932-33), using the saccharine method, showed that variations in repeated tests on his series of 162 subjects were small. Esser and Berliner (1943) on the other hand, using the same technique, came to the opposite conclusion; their observations, made on 60 patients, 26 of whom suffered from heart disease, showed that when paired tests were performed, similar results were obtained in 6 instances only, while the others showed differences ranging from 1-143 per cent of the initial time. Our observations show a much smaller variation than theirs, the greatest being 27 per cent change between paired measurements. This variation is small when compared with the range of normality found in a large series of volunteers (Wright et al., 1948). We feel, therefore, that, while it is doubtful whether differences of a few per cent are of any significance in any single subject, it is nevertheless justified to regard similar changes in average flow-rates as of greater reliability where the data are obtained from groups.

Interest has been taken in the past in the changes produced in flow-rates by variations in posture. All published figures show a slowing of the venous flow-rate when the subject rises from the lying to the standing posture. Thompson et al. (1928), using the brilliant vital red method, showed that in their series, the arm-foot time changed from 45-60 sec. in the recumbant position to 120-150 sec. when the subject stood up. In the following year, Bock et al. (1930), using the histamine technique, obtained comparable results, while more recently, Kvale and Allen (1939) and Kvale et al. (1940), have further confirmed these observations. Much other supporting evidence on the hæmodynamics of postural changes has also been put forward, all of which show that the effect of gravity is to reduce the velocity of the venous stream in the lower limbs (Waterfield, 1931; Wilburne, 1942; Starr, 1943; Starr and Maycock, 1945; Wilkins et al., 1950). Our observations provide further support for the belief that the flow-rate is greatly decreased when the subject rises. This retardation may well be a potent factor in the onset of syncope that occurs in persons kept standing upright for considerable periods, as with troops on parade. Concurrent with and dependent upon the decrease in flow-rate, the venous pressure in the legs rises (Pollack and Wood, 1949), fluid passes out into the surrounding tissues and œdema develops. At the same time, the failure of venous return from the legs causes a diminution of cardiac output (Brigden et al., 1950) and fainting may occur.

The same effect is observed, though to a lesser degree, in the sitting position with the legs down. Pollack and Wood (1949) showed that the pressure in the saphenous veins rose in both standing and sitting postures, and it is probable that their observations are dependent upon the reduction of flow-rate demonstrated by our method.

Since it has been suggested that pressure behind the knees may be a factor in reducing venous flow-rate, measurements were made in the crossed-knee sitting posture. The subject was asked to cross the knees in the most comfortable and natural manner and to remain for five minutes without moving. The upper (crossed-over) foot, into which the injection was made is not fully dependent in this attitude, and the knee is higher than the groin. The flow-rates recorded were very variable from subject to subject; the average for the group being slightly greater than that for the standard position. Statistically, the difference between the crossed-knee sitting and standard positions was not significant. The pressure exerted behind the knee in this naturally comfortable posture was not great and the effect noted by Simpson (1940), on the importance of such pressure on the incidence of pulmonary embolism, was not reproduced. 
The increased rate of flow in the lower limbs that occurs when the body is tipped head downwards was studied in animals by Hill (1895) more than half a century ago and was ascribed by him to the effect of gravity. His observations have been used from time to time as an argument in favour of nursing surgical cases with the foot of the bed raised (Oschner, 1946) for at least a part of the day until the patient is sufficiently recovered to make voluntary muscular contractions of the legs. By elevating the leg from the horizontal position, Kvale et al. (1940) demonstrated a decrease of 8-25 per cent in the foot/carotid time and Wilkins et al. (1950) reported that, in the head-down position, venous pressure in the feet and legs fell almost to that of the atmosphere. Our flow-rate measurements also have shown that venous velocity is markedly increased when the subject is tipped with the head 10 degrees down; the rate is almost double that found in the horizontal position. In view of this finding, therefore, it appears that the practice of raising the bed foot for short periods in those cases that are immobilized may well be a good prophylactic against the onset of thrombosis, especially in patients where other factors in the pathogenesis of coagulation are minimal. It was previously shown that in bed-ridden surgical patients, a progressive decrease of the venous flow-rate occurred in the lower limbs (Wright et al., 1951), while in those who were ambulatory early in convalescence, no such slowing of the venous stream was demonstrable. Any measure that can increase the rate of blood flow in the legs of patients nursed in bed may, therefore, be of practical value. At the same time Frykholm (1940) has pointed out that to keep the foot of the bed raised for long periods may damage the veins of the leg by allowing the intimal surfaces to come into contact with each other, and thus injure the cells.

The effect of exercise on venous flow has been investigated in various ways. In all reports the rate has been shown to increase with exercise (Thompson et al., 1927; Kvale and Allen, 1939; Kvale et al., 1940; Heller, 1942; Pollack and Wood, 1949; Wilkinson et al., 1950; Gollwitzer-Meier, 1950). The types and degrees of exercise varied from one report to another, as also the method of measuring the change. The present findings, however, of an increased venous flow-rate of between two and three times that in the standard supine position is of the same order of magnitude as those of other observers. It is of interest that such a profound change should be produced by so small a movement as dorsi- and plantar-flexion of the foot and it appears that this simple exercise offers a satisfactory method of ensuring a rapid venous flow-rate in those patients who must be kept recumbent. Even the old and frail, or the seriously ill can be required several times a day to perform the simple " pedalling" movement shown here to be so effective in combating venous stasis.

\section{SUMMARY}

Venous velocities, measured by an injection of ${ }^{24} \mathrm{NaCl}$, have been shown to be equal in both legs. Day-to-day measurements in normal subjects, under standard conditions have been shown to fluctuate by about 25 per cent of the initial flow-rate.

A comparison of venous velocity in the horizontal and various other positions has been made, and figures are given for the mean flow-rates observed. Venous flow-rate is about halved when the subject stands or sits when compared with that in the supine position. Venous flow-rate is doubled when the subject is tipped head-downwards or after vigorous dorsi- and plantar-flexion of the foot.

The significance of these findings is discussed with special reference to the incidence of venous thrombosis.

This study was supported by a grant from the Medical Research Council.

\section{REFERENCES}

Atkins, H. J. B. (1938). Guy's Hosp. Rep., 18, 92.

Barker, N. W., Nygaard, K. K., Walters, W., and Priestly, J. T. (1941). Proc. Staff. Meet. Mayo. Clin., $16,33$.

Bock, A. V., Dill, D. B., and Edwards, H. T. (1930). J. Clin. Invest., 8, 533.

Brigden, W., Howarth, S., and Sharpey-Schafer, E. P. (1950). Clin. Sci., 9, 79.

Cordier, A. H. (1905). J. Amer. med. Ass., 45, 1792.

Esser, K. H., and Berliner, K. (1943). Ann. intern. Med., 19, 64 
Fishberg, A. M., Hitzig, W. M., and King, F. H. (1932-33). Proc. Soc., Exp. Biol. Med., 30, 651.

Frykholm, R. (1940). Surg. Gynec. Obstet., 71307.

Gollwitzer-Meier, K. (1950). Lancet, 1, 381.

Hall, Marshall (1832). Med. Chir. Trans., 17, 250.

Heller, R. E. (1942). Surg. Gynec. Obstet., 74, 1118

Hill, L. (1895). J. Physiol., 18, 15.

Hunter, W. C., Sneeden, U. D., Robertson, T. D., and Snyder, G. A. C. (1941). Arch. intern. Med., 68, 1.

Ingram, E. S. (1942). Canad. med. Ass. J., 47, 553.

Kvale, W. F., and Allen, E. V. (1939). Amer. Heart J., 18, 519.

Smith, L. A., and Allen, E. V. (1940). Arch. Surg., 40, 345.

Osborn, S. B., and Wright, H. P. (1949). Brit. J. Radiol., 22, 110.

Oschner, A. (1946). J. Amer. med. Ass., 132, 827.

Piorry, P. A. (1826). Arch. gén. Méd., 12, 527.

Pollack, A. A., and Wood, E. H. (1949). J. Appl. Physiol., 1, 649.

Simpson, K. (1940). Lancet, 2, 744.

Starr, I. (1943). J. Clin. Invest., 22, 813.

, and Maycock, R. L. (1945). Amer. J. med. Sci., 210, 701.

Thompson, W. O., Alper, M., and Thompson, P. K. (1927-28). J. Clin. Invest., 5, 605.

Waterfield, R. L. (1931). J. Physiol., 72, 110.

Wilburne, M. (1942). Amer. Heart J., 24, 816.

Wilkins, R. W., Mayer, H. H., and Litter, J. (1950). Circulation, 2, 373.

Wright, H. P., Osborn, S. B., and Edmonds, D. G. (1948). Lancet, 2, 767.

(1951). Lancet, 1, 22

Zilliacus, H. (1946). Acta. med. Scand., Suppl. 171. 